\title{
Two energy storage alternatives for a solar-powered sustainable single floor desert home
}

\author{
M. A. Serag-Eldin \\ Mechanical Engineering Department, American University in Cairo, \\ Egypt
}

\begin{abstract}
This paper is concerned with the thermodynamic analysis of a totally solarpowered desert home. The home is air-conditioned and provides all modern comforts and facilities. It features closely spaced, roof mounted photovoltaic modules, which collect the solar energy driving the whole energy system. During the day time, the modules form an elevated horizontal surface above the roof, shielding it from direct solar radiation. After sunset, the photovoltaic modules are flipped vertically upwards to expose the roof to the sky, thus enhancing night-time cooling.

Two methods of energy storage are proposed and compared, one using solely battery storage of electrical output, and the other employing a combination of cold water storage and battery storage. The analysis is based on detailed dynamic heat transfer calculations for the entire building envelope, coupled with a solar radiation model, and followed by energy balances. The results reveal that indeed it is feasible to employ solar energy as the only source of energy to power the home, and that each storage system has its own merits and shortcomings.
\end{abstract}

Keywords: zero energy house, solar energy, desert building, energy storage, renewable energy.

\section{Introduction}

Many middle-eastern countries feature desert environments, and vast resources of relatively cheap energy in the form of oil. Most inhabitants thus enjoy modern air-conditioned homes with several TV sets, computers, automatic clothes and 
dish-washers, and other energy consuming applications. However, this source of energy is finite; hence, sustainability of the quality of life they are presently enjoying requires reliance on renewable energy resources.

Moreover, even with today's cheap energy resources, connecting centralized production through an electrical grid to remote secluded desert sites with small communities is very costly.

Fortunately, open desert sites provide an abundance of local renewable energy source in the form of solar energy. Exploitation of this source provides sustainability for future generations, as well as a present day economically viable alternative to local small scale fossil-fuelled generators. However, solar energy is available only during daylight hours, and even then its intensity varies considerably throughout the day, and from month to month. To depend entirely on solar energy, the energy conversion system must incorporate suitable storage.

Recently, Serag-eldin [1] proposed an integrated energy design for a desert "zero-energy-house"; i.e. a self-sufficient desert home which relies entirely on good energy conservation measures, local solar energy conversion, and electric energy storage to reach complete independence from the electrical grid. In the present work, two methods of storage are investigated; one using solely battery storage of the electricity produced by photovoltaic modules, and the other employing a combination of both cold-water storage and battery storage. Both systems are analyzed, compared and discussed. The output results are based on a detailed dynamic heat transfer analysis for the entire building envelope, coupled with a solar radiation model, and followed by overall energy balances.

\section{Conceptual home design}

For demonstration purposes, a conceptual, one floor house of $3 \mathrm{~m}$ wall height and $15 \mathrm{~m} \times 15 \mathrm{~m}$ foot-print is considered. A large array of Photovoltaic modules is positioned on a horizontal plane approximately $0.2 \mathrm{~m}$ above the roof top. The modules cover the entire horizontal surface whose boundaries extend $1 \mathrm{~m}$ beyond the exterior walls in each direction. The purpose of the overhang being to both, provide an increased area for the photovoltaic modules (solar energy capture area), and partial shading of side-walls and windows from direct beam radiation, thus decreasing cooling load.

The modules are fixed to a linkage mechanism which allows them to split, fold and rotate to a vertical position. During daylight hours the modules are horizontal (or nearly so) in order to collect the short-wave solar radiation from the sky, and to protect the roof surface from direct beam radiation. After sunset and until sun-rise, the modules are automatically folded and rotated to point vertically upwards, thus enhancing heat loss from the roof top by long wave infra-red radiation exchange with the sky (which is substantial in desert environments). The roof also includes insulation material.

The building side walls comprise a $0.06 \mathrm{~m}$ external sandstone cladding, followed by two $0.12 \mathrm{~m}$ red brick walls separated by a 0.01 to $0.05 \mathrm{~m}$ air gap. Research has shown that due to the appearance of natural convection effects for air-gaps greater than $0.01 \mathrm{~m}$, the overall thermal resistance in this range is almost 
constant (Kreider and Rabl [2]); hence calculations are made here for conductive resistance only, with a representative air gap of $0.01 \mathrm{~m}$; but in implementation a $0.05 \mathrm{~m}$ air gap would be more practical and likely. The internal wall is covered by a $0.03 \mathrm{~m}$ layer of plaster. The roof surface comprises a lower $0.02 \mathrm{~m}$ plaster layer, above which is a $0.12 \mathrm{~m}$ concrete layer, covered by $0.10 \mathrm{~m}$ of mortar and asbestos insulation, followed by a $0.06 \mathrm{~m}$ thick layer of gravel. The windows are state of the art, of double or triple glazing design and with selective surfaces to reduce solar heat gains; a U-value of $1 \mathrm{~W} / \mathrm{m}^{2} \mathrm{~K}$ and solar-heat-gain coefficient, $\mathrm{F}$ $=0.5$ is assumed, which is typical of such windows (ASHRAE [3]). The total window surface area is $15 \%$ of the total side-wall area.

The internal room temperatures are maintained uniform at $25^{\circ} \mathrm{C}$ by a conventional air-conditioning system, and the nominal number of occupants is 6 persons. Displacement ventilation (e.g. Serag-eldin [4]) is employed to improve air quality. The conversion efficiency of the photovoltaic cells, $\eta_{\mathrm{c}}$ is assumed to be $12 \%$ which is typical of today's common commercial modules.

When applicable, cold water storage is created by excess cooling capacity during daylight hours. The air-conditioning system is assumed to comprise a water chiller, a fan-coil unit and two well insulated water reservoirs, one at near chiller-inlet temperature and the other at near chiller-outlet temperature. The fan coil unit draws chilled water straight from the cold-water store, and returns it to the warmer water reservoir. The chiller unit operates only during the sunniest hours of the day, the cold water generated during those hours being sufficient to cover the total daily air-conditioning load. The battery storage in this case is only required to store electrical energy for the other loads.

If only battery storage is provided, then the water chiller operates all hours of the day, driven by electrical power supplied by battery storage or photovoltaic cells upon availability.

The site is specified to be at a latitude-angle $\lambda=20^{\circ}$. Mean ambient temperatures of $25^{\circ} \mathrm{C}$ and $35^{\circ} \mathrm{C}$ are assumed on December $21^{\text {st }}$ and June $21^{\text {st }}$, respectively. Ambient temperature are assumed to peak at solar noon and follow a sinusoidal profile throughout the day, with an amplitude of $10{ }^{\circ} \mathrm{C}$. The house is oriented such that side walls are facing pure East, West, North and South.

\section{Mathematical model}

The sun is both the energy source and the main contributor to the energy loads; namely the cooling load. Hence, accurate prediction of solar radiation intensity and direction is a necessity for accurate performance estimates. A Solar radiation model which predicts angles and intensities for different positions on Earth, clearness of sky, time of day and day of year, and predicts each of the direct beam component (Hottel [5]) and diffuse component (Liu and Jordan [6]) is employed, assuming clear sky conditions.

It is coupled to a heat transfer model which solves a parabolic partial differential equation for heat conduction, coupled with radiation models at nonsolid surfaces and convective boundary conditions. The equations are solved 
using a control-volume method (e.g. Versteeg and Malalasekera [7]). Details of the model may be found in Serag-eldin [1].

\section{Temperature distributions}

Predictions are made here for two key days, one displaying the shortest day of the year, December $21^{\text {st }}$, and the other the longest, June $21^{\text {st }}$.

\subsection{Temperature profiles on December $21^{\text {st }}$}

Figure 1 displays the temperature variations with time for December $21^{\text {st }}$ at the South facing wall neglecting end effects, i.e. near ground and roof effects. The profiles display the variations at the internal surface adjacent to room (Tin_surf), the external surface adjacent to outside environment (Text_surf), and at the centre of the air gap between the double walls (Tair_gap). For comparison reasons, the ambient temperature (Tamb) is also displayed. The temperature units are in degree Kelvin, and the time is in hours, with "12" corresponding to solar noon.

In December the ambient temperature is generally lower than wall temperatures; thus heating is due mainly to solar radiation and not convection. Due to the thermal capacity of the walls, the peak temperatures on the walls do not occur at noon, but later in the day, the further the section from the external surface the more the shift; at the inner surface the shift is almost 12 hours. This, together with the relatively low overall conductivity of wall, results in Tin_surf being almost uniform at a temperature of approximately $299 \mathrm{~K}$.

Figure 2 displays the temperature profiles at the East facing wall. Compared to Figure 1, it is noticed that the external surface temperature warms up earlier in the day, and its profile is less peaked; this is because of more solar heating earlier in the day, since the sun rises from the East direction. At other sections, the thermal capacity and limited penetration effects are more dominant and profiles are more in line with Figure 1.

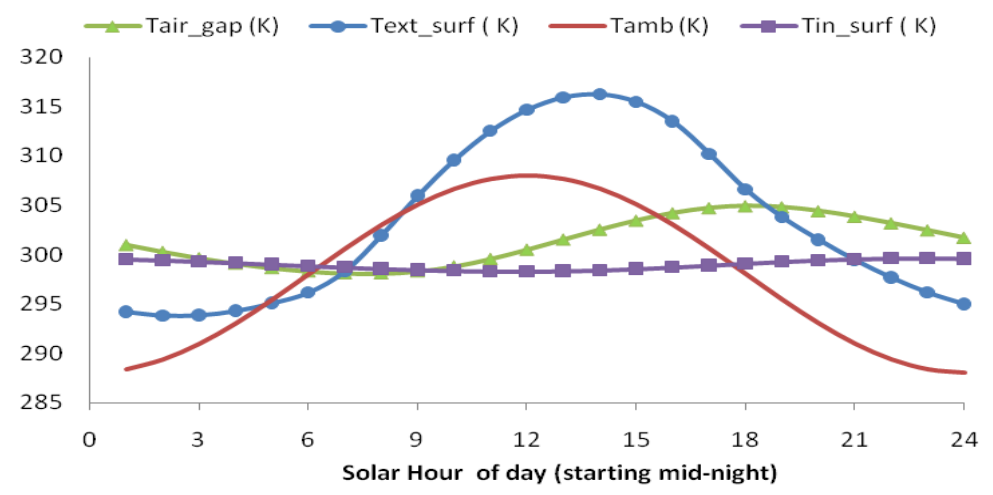

Figure 1: $\quad$ Temperature variations for South facing wall, Dec $21^{\text {st }}$. 


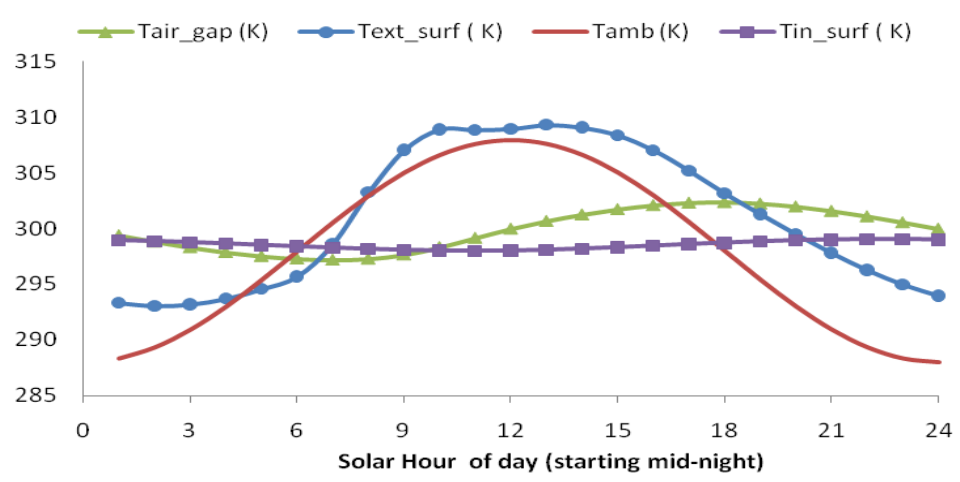

Figure 2: $\quad$ Temperature variations for East facing wall, Dec $21^{\text {st }}$.

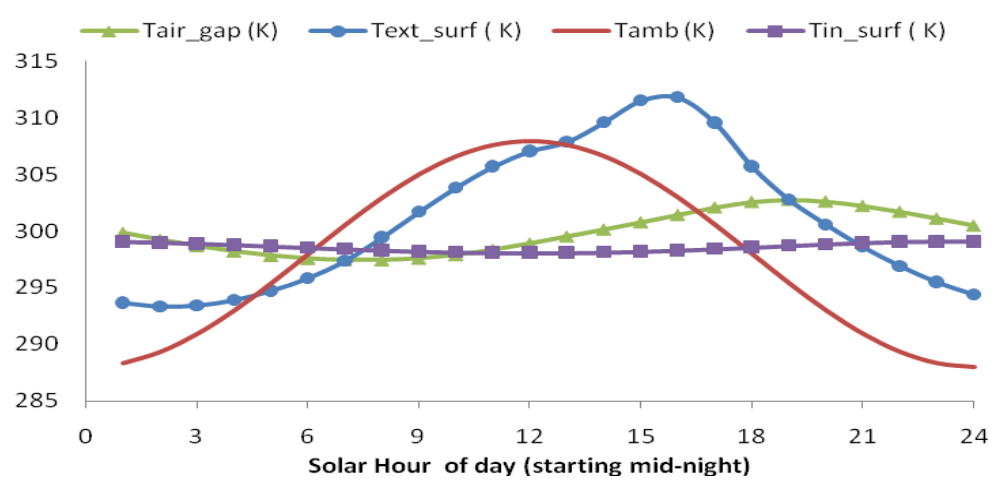

Figure 3: Temperature variations for West facing wall, Dec $21^{\text {st }}$.

Figure 3 displays the corresponding profile for the West facing wall. As expected, the peak external wall temperature occurrs much later in the day, compared to Figure 2 and also Figure 1.

Figure 4 displays the corresponding results on the Northern wall. The peak external wall temperature is considerably cooler in this case than in the other three; which should be expected since the northern face does not receive direct beam solar radiation. However, it is interesting to observe that for all 4 surfaces, the minimum room-side temperature occurrs at solar noon, due to the large thermal capacity of the walls and the good insulation properties of air gap.

Figure 5 reveals the corresponding roof temperature variations. The profiles display the roof internal temperature (Tin roof) adjacent to the room and the external roof temperature (Text roof), together with the ambient temperature.

It is noticed that the external roof temperature is most of the time lower than the ambient temperature and that for approximately half the time it is lower than room temperature $(298 \mathrm{~K})$ as well. This is due mainly to the considerable night time cooling of the roof through long-wave infrared-radiation heat-exchange with the sky; for approximately 14 hours/day on December $21^{\text {st }}$. The latter is calculated as radiation exchange between roof-top and sky at ambient 
temperature plus a recommended (ASHRAE[3]) correction factor of $63 \mathrm{~W} / \mathrm{m}^{2}$. The true correction factor for clear sky desert environment is expected to be even greater, rendering our estimates of the cooling load more conservative.

\subsection{Temperature profiles on June $21^{\text {st }}$}

Figures 6-10, display the results for June $21^{\text {st }}$ which correspond to Figures 1-5, respectively, for December $21^{\text {st }}$.

Comparison of like figures shows immediately that now the wall temperatures and air gap temperatures are considerably higher than the room temperatures, indicating considerably larger heating from outdoors. The number of daylight hours is also larger, adding to the total daily heating. This is reflected in a slightly higher room-side surface temperature. Since the latter affects the cooling load via the radiation and convective heat transfer with the room interior, the resulting cooling loads are also higher, as will be shown later.

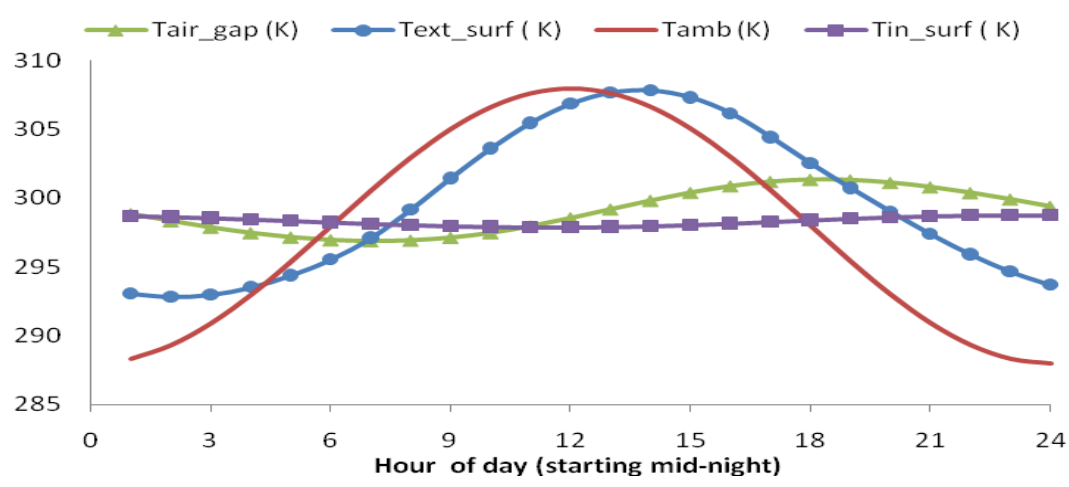

Figure 4: Temperature variations for North facing wall, Dec $21^{\text {st }}$.

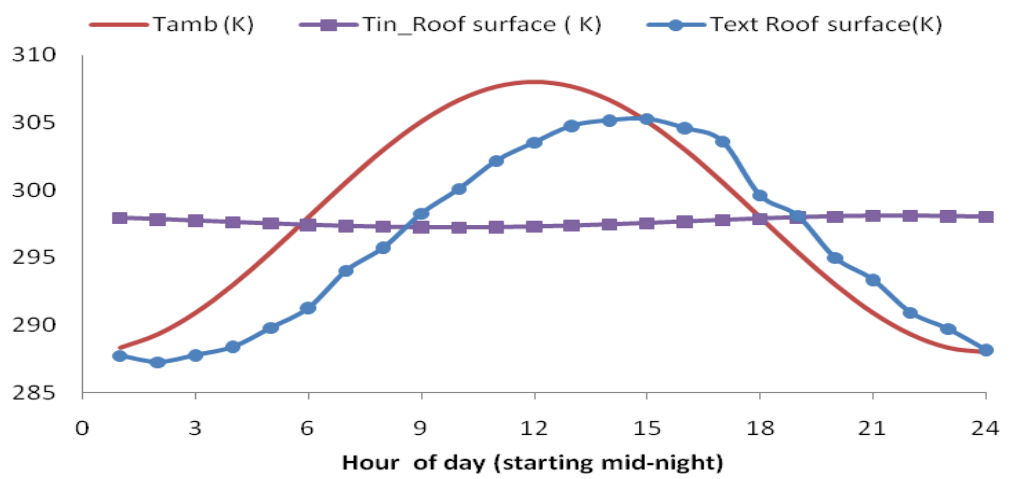

Roof, $\lambda=20^{\circ}, V=m / s$ December $21^{\text {st }}$

Figure 5: Temperature variations for roof, Dec $21^{\text {st }}$. 


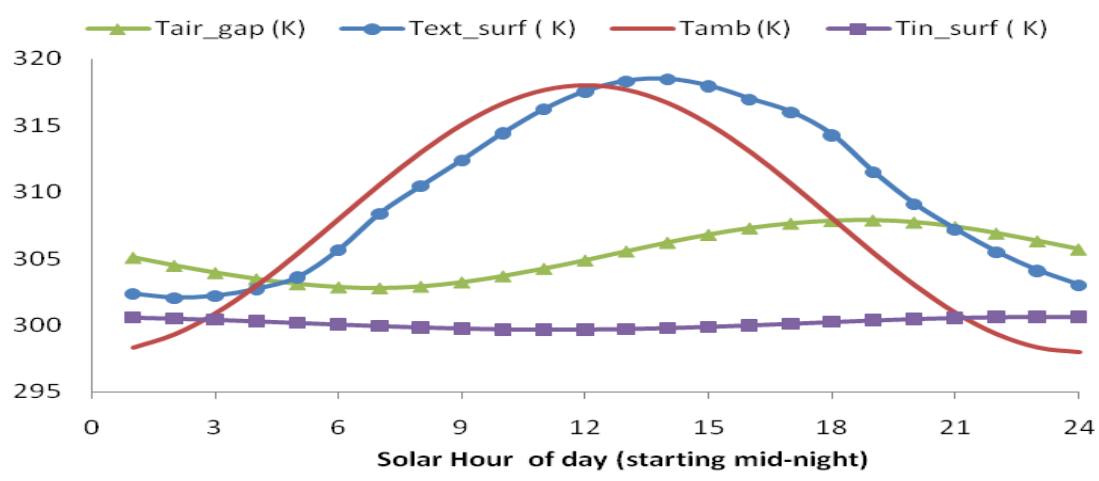

South Facing Wall, $\lambda=20^{\circ}$, June $21^{\text {st }}$

Figure 6: Temperature variations for South facing wall, June $21^{\text {st }}$.

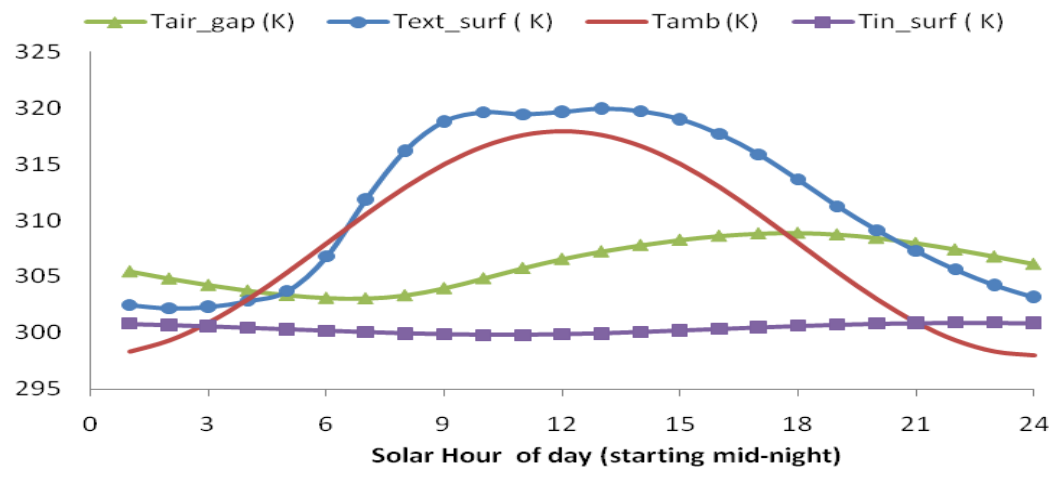

East Facing Wall, $\lambda=20^{\circ}$, June $21^{\text {st }}$

Figure 7: $\quad$ Temperature variations for East facing wall, June $21^{\text {st }}$.

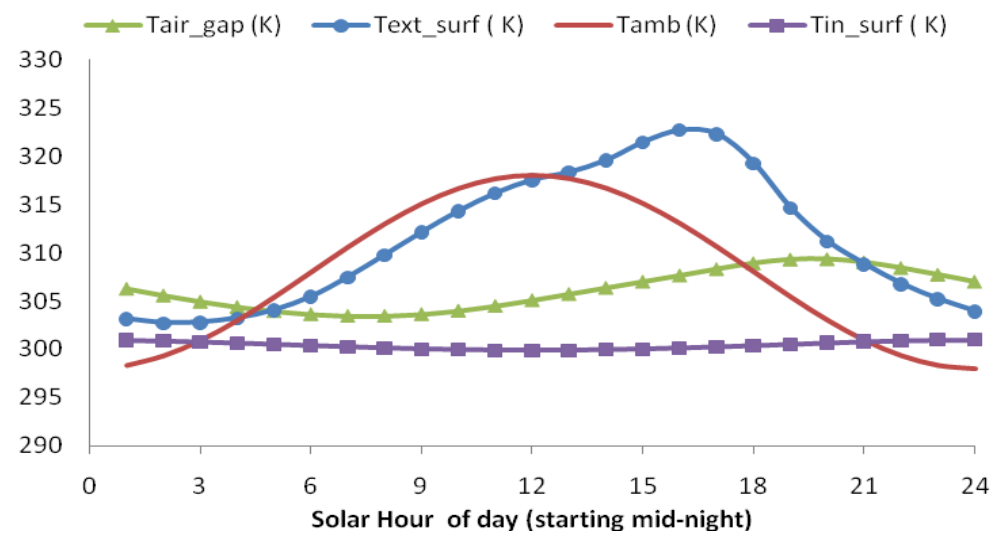

Figure 8: Temperature variations for West facing wall, June $21^{\text {st }}$. 


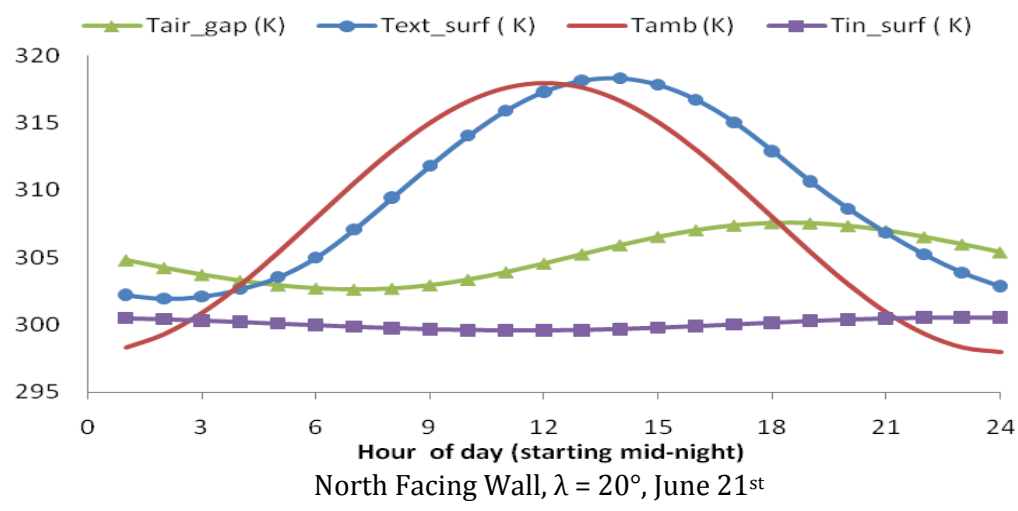

Figure 9: Temperature variations for North facing wall, June $21^{\text {st }}$.

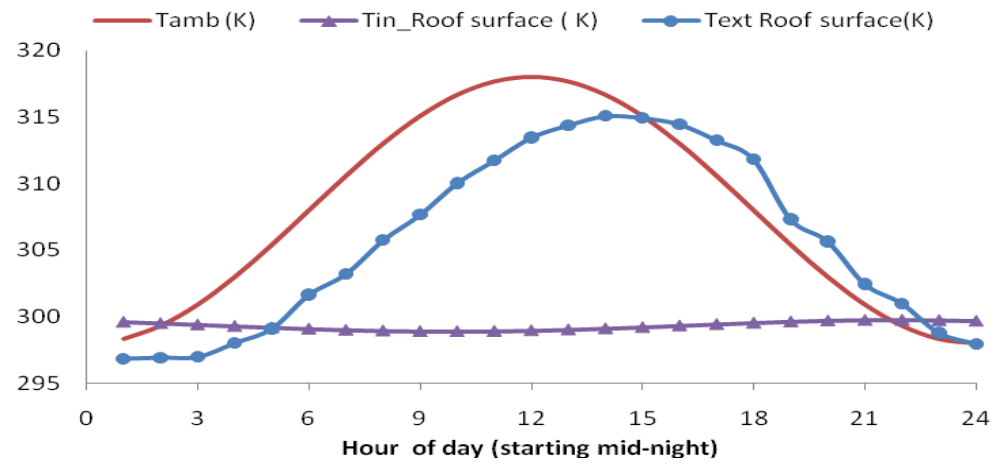

Figure 10: Temperature variations for roof, June $21^{\text {st }}$.

\section{Cooling loads}

The expected cooling loads may be classified into (Serag-eldin [1]):

i) envelope cooling load (side walls, roof and windows)

ii) fresh air and infiltration cooling load

iii) heat generated by lighting equipment

iv) sensible heat generated by occupants

v) heat generated by electrical appliances

Figure 11 shows the breakdown of cooling loads for Decmber $21^{\text {st }}$. The sum of roof and side wall loads is generally small, and minimum at solar noon; this is due to the good insulation and large thermal capacity of walls and roof. On the other hand, the window cooling load rises quickly during daylight hours, while it is slightly negative after sunset. The sum of other cooling loads also peaks at noon, because of the effect of ambient temperature on fresh air and infiltration loads. The total cooling load is maximum at solar noon and its variation throughout the 24 hours is within approximately $50 \%$ of peak load. 


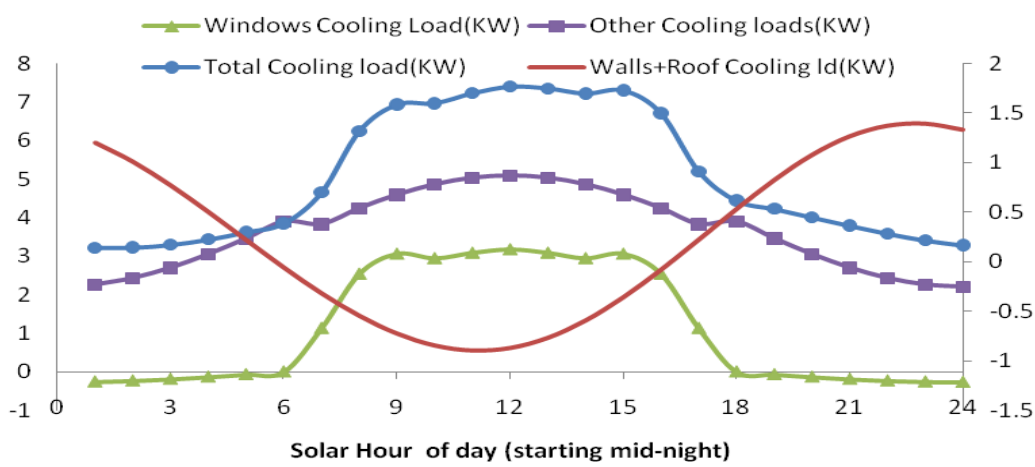

Figure 11: Breakdown of cooling loads, December $21^{\text {st }}$.

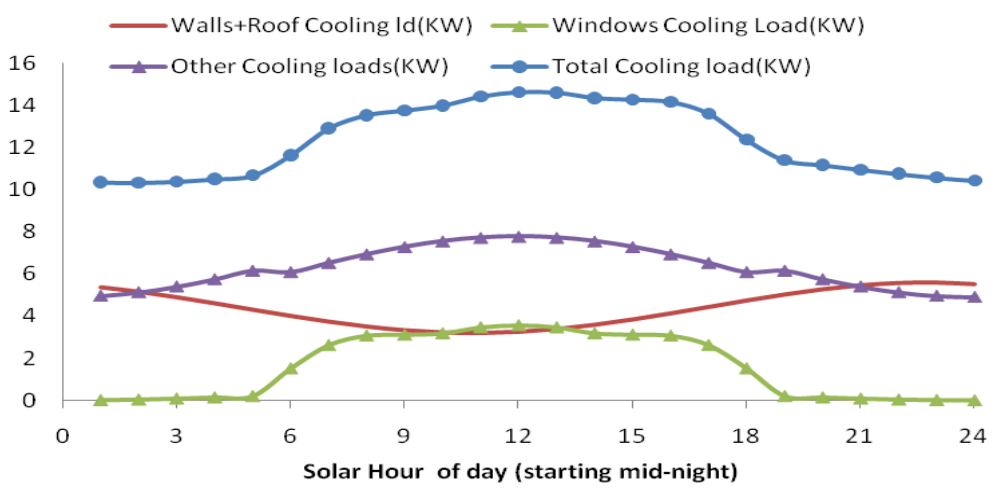

Figure 12: $\quad$ Breakdown of cooling loads, June $21^{\text {st }}$.

Figure 12 shows the corresponding loads on June $21^{\text {st }}$. Comparing the two diagrams reveals that the load in summer is double that in winter, and is much more uniform, varying within approximately $30 \%$ of peak load.

\section{Storage calculations}

\subsection{Battery Only Storage System (BOSS)}

The instantaneous rate of electricity production by the photovoltaic modules $P_{V}$ is derived from:

$$
P_{V}=\eta_{c} I_{G}
$$

where $I_{G}$ is the instantaneous horizontal solar irradiance. The instantaneous rate of charge of the battery, $P_{B}$, is thus

$$
P_{B}=P_{V}-P_{\text {light }}-q_{\text {cool }} / C O P-P_{\text {elec }}
$$


where $P_{\text {light }}$ is the electrical lighting load; $q_{\text {cool }}$ is the cooling heat-load and $C O P$ is the coefficient of performance of the cooling equipment (assumed to be 3); $P_{\text {elec }}$ is the available electrical load for driving appliances such as TV sets, refrigerators, dish-washers, multi-media, computers, pumps and fans. Using efficient lighting, it is assumed that $P_{\text {light }}=500 \mathrm{~W}$ between sunset and sunrise and zero at other times. $P_{\text {elec }}$ is output from the calculations such as to balance demand and supply, and is taken to be uniform over the day, but essentially varies from day to day. When $P_{B}$ is positive, the battery is charging and when negative the battery is discharging.

The charge $E_{b}$ in the battery at any instant of time relative to the charge at midnight ( $\mathrm{t}=0 \mathrm{hr}$.) is expressed by:

$$
E_{B}=\int_{0}^{t} P_{B} \cdot d t=\int_{0}^{t}\left(P_{V}-P_{\text {light }}-P_{\text {elec }}-q_{\text {cool }} / \text { C.O.P. }\right) . d t
$$

where $P_{\text {elec }}$ is selected to yield $E_{b}=0$ at the start of the next cycle, i.e. at $\mathrm{t}=24 \mathrm{~h}$.

Figure 13 reveals rate of electricity generation, rate of battery charging and the electrical charge in the battery at any hour of the day, for December $21^{\text {st }}$, with a daily average value of $P_{\text {elec }}=3 \mathrm{~kW}$; i.e. $72 \mathrm{kWh} /$ day. This value is very generous; for example, the average household electricity consumption in UK, including heating load is only $11 \mathrm{kWh} /$ day (Boyle [8]). It is noticed that the battery will only start charging at around $8 \mathrm{a} . \mathrm{m}$. and continue to do so until 4 p.m.; the rest of the time the battery is discharging. The minimum and maximum battery charge occur during those times as well. The theoretical minimum battery storage capacity is given by the difference between maximum and minimum charges, which for this case is $70.16 \mathrm{kWh}$. The minimum air-conditioning equipment capacity is $7.39 \mathrm{~kW}$, operating round the clock.

Figure 14 shows the corresponding results for June $21^{\text {st }}, P_{\text {elec }}=4 \mathrm{~kW}$ for this case. Thus although the cooling load has doubled since December $21^{\text {st }}$, the greater solar energy available on June $21^{\text {st }}$ has more than made-up for that. However, the minimum air-conditioning equipment cooling capacity is now 14.6 $\mathrm{kW}$, and the minimum theoretical battery storage required is $105.4 \mathrm{kWh}$. In

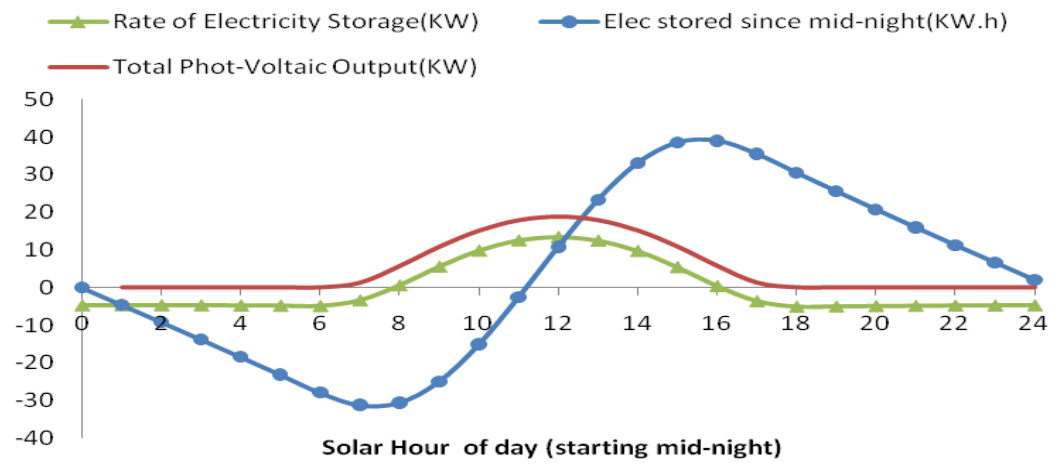

Figure 13: Electricity generation and storage for battery only system, Dec $21^{\text {st }}$. 


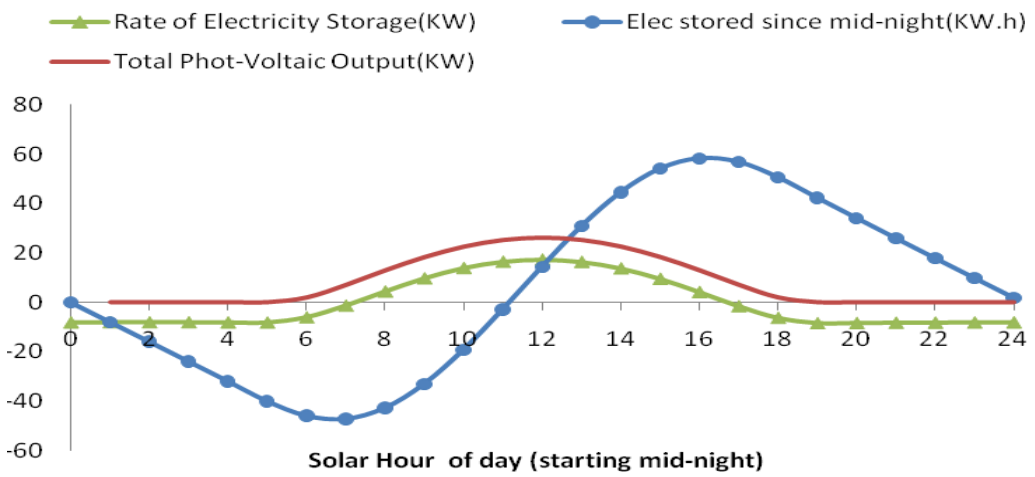

Figure 14: Electricity generation and storage for battery only system, June $21^{\text {st }}$.

practice, batteries are not allowed to discharge fully, and considerably larger storage capacity may be required, depending on type of battery.

\subsection{Combined Cold-water and Battery Storage (CWBS)}

Here it is planned to operate the cooling equipment only on the sunniest hours of the day, $\Delta \mathrm{t}_{\mathrm{s}}$, during which time they must provide the instantaneous cooling load $q_{\text {cool }}$, and cooling of additional chilled water to be stored for use at other times, $q_{\text {stor }}$. Taking $q_{\text {stor }}$ to be uniform during equipment operation, it is derived from

$$
q_{\text {stor }}=\left[\int_{0}^{12-\Delta t_{s} / 2} q_{\text {cool }} \cdot d t-\int_{12+\Delta t_{s} / 2}^{24} q_{\text {cool }} \cdot d t\right] / \Delta t_{s}
$$

Since the cooling equipment is driven by the photovoltaic modules, the energy available for battery charging in this case is only

$$
P_{B}=P_{V}-P_{\text {elec }}-P_{\text {light }}-\left(q_{\text {cool }+} q_{\text {stor }}\right) / \text { C.O.P. } .
$$

The volume of chilled water in the cold-water store relative to volume at midnight, $V_{C W}$, is at any hour of day

$$
V_{C W}=\left[\int_{0}^{t}\left(q_{A / C}-q_{c o o l}\right) \cdot d t\right] /\left(\rho c_{p} \Delta T_{C W}\right)
$$

where $q_{A / C}$ is the cooling (air-conditioning) equipment output; $\rho$ and $\mathrm{c}_{\mathrm{p}}$ are the density and specific heat of the water; and $\Delta T_{C W}$ is the temperature difference between the chiller inlet and outlet. During operation of the air-conditioning equipment $q_{A / C}$ is the sum of $q_{\text {cool }}$ and $q_{\text {stor }}$, else $q_{A / C}=0$.

Figure 15 displays the profiles for $q_{A / C}, P_{B}, P_{V}, E_{B}$, and $V_{C W}$, at all hours of the day on June $21^{\text {st }}$; the corresponding diagram for December is not displayed since 


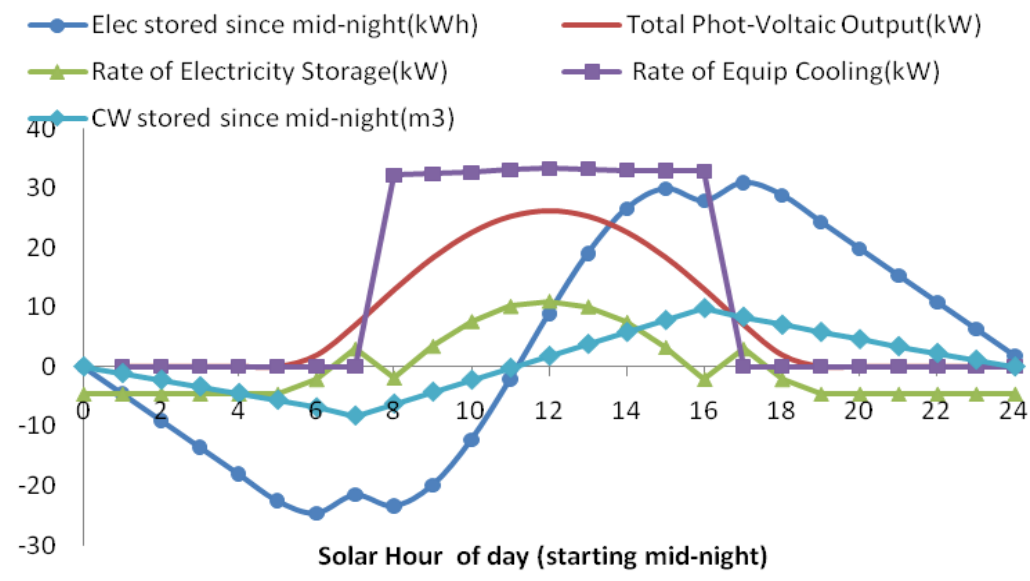

Figure 15: Combined cold-water and battery storage system, June $21^{\text {st }}$.

the design capacities will be dictated by the June $21^{\text {st }}$ requirements only. For this case $P_{\text {elec }}=4 \mathrm{~kW}, \Delta \mathrm{t}_{\mathrm{s}}=9 \mathrm{hrs}$ and $\Delta T_{c w}=10^{\circ} \mathrm{C}$. The theoretical minimum battery storage and chilled water storage capacities are $54.4 \mathrm{kWh}$ and $18.1 \mathrm{~m}^{3}$, respectively. The minimum cooling capacity for the air-conditioning system operating 9 hours daily is $33.3 \mathrm{~kW}$.

It is noticed that both the battery storage and cold-water storage are minimum at approximately the same time, which should be expected since they are driven by the same source, namely photovoltaic cells. Comparison against Figure 13, demonstrates that introduction of the cold storage has substantially reduced the required battery storage capacity.

\section{Comparison between storage options}

i) the CWBS option needs only about half the battery storage of the BOSS.

ii) battery storage is relatively expensive and requires frequent renewal of batteries. The theoretical minimum additional capacity in BOSS is $51 \mathrm{kWh}$; however, possibly double this capacity may be needed to avoid discharging the battery to dangerously low levels.

iii) the CWBS requires 2 well insulated $18 \mathrm{~m}^{3}$ water container; but it is mainly a one-time cost. It may be built underneath the floor of the building to minimize space waste and reduce heat transfer losses.

iv) both storage systems suffer storage losses; batteries from their chargedischarge characteristics and chilled water storage from unwanted heat gains from surroundings. The latter may be reduced by additional insulation, but at a price. In the present analysis the storage efficiency $\eta_{\mathrm{st}}=80 \%$ for both; albeit this could be too optimistic for batteries and too low for well insulated chilled water storage.

v) chilled water storage is more environmentally friendly and less hazardous than battery storage. Moreover, stored water may be used in an emergency for other purposes, e.g. fire fighting. 
vi) reliability of cold water storage is likely higher than that of battery storage.

vii) the biggest disadvantage of the CWBS is the increased capacity of chiller, which is more than double that of the BOSS. This entails increased equipment cost and space, although partially offset by the longer life of the equipment since it operates only $9 \mathrm{hrs} /$ day, as opposed to $24 \mathrm{hrs}$ for BOSS.

\section{Summary and conclusion}

Heat transfer computations and energy system balances are made for an energy efficient desert home designed to be totally powered by roof mounted photovoltaic cells. The results of the calculations demonstrate that it is indeed possible to cover the house energy needs entirely by solar energy using photovoltaic modules, provided adequate energy storage is provided. A comparison is made between BOSS and CWBS which reveals the merits and flaws of each. However, the selection should be based on a total life cost analysis, which is site specific and outside the scope of this study.

\section{Acknowledgements}

This work was funded by the King Abdalla University for Science and Technology (KAUST) project on Integrated Desert Building Technologies, grant\#09c032500100831 held by AUC.

\section{References}

[1] Serag-eldin, M.A. Thermal Design of a Fully Equipped Solar-Powered Desert Home, accepted for publication in Proc. of $1^{\text {st }}$ Int. Nuclear and Renewable Energy Conf. (INREC10), Amman, Jordan, March 21-24, 2010.

[2] Kreider, J.F. and Rabl, A. Heating and Cooling of Buildings: Design for Efficiency, McGraw-Hill Inc., New York, 1994.

[3] ASHRAE Fundamentals Handbook, American Society of Heating, Refrigerating and Air-Conditioning Engineers, Inc., Atlanta, USA, 2009.

[4] Serag-Eldin, M.A. "Displacement Ventilation for Efficient Air-conditioning and Ventilation of GYMs", Proc. of Heat-SET-2007 Conference, Chambery, France, 18-20 April, 2007, paper \# P-128

[5] Hottel, H.C. "A Simple Model for Estimating the Transmissivity of Direct Solar Radiation through Clear Atmospheres," Solar Energy, vol.18, 1976, p.129.

[6] Liu, B.Y.H. and Jordan, R.C. "The Interrelationship and Characteristic Distribution of Direct, Diffuse and Total Solar Radiation." Solar Energy, vol.4, p.34, 1960.

[7] Versteeg, H.K. and Malalasekera, W. An Introduction to CFD: The Finite Volume Method, Longman Group, Essex, England, 1995.

[8] Boyle, G. Renewable Energy: Power for a Sustainable Future, Oxford University Press, U.K., 2004. 